WILEY-VCH

\title{
Reversible Delithiation of Disordered Rock Salt $\mathrm{LiVO}_{2}$
}

\author{
Christian Baur, ${ }^{[a]}$ Johann Chable, ${ }^{[a]}$ Franziska Klein, ${ }^{[a]}$ Venkata Sai Kiran Chakravadhanula, ${ }^{[a,+]}$ and \\ Maximilian Fichtner*[a,b]
}

Abstract: A rigid crystal lattice, where cations occupy specific positions in the lattice, is generally regarded a critical requirement to enable $\mathrm{Li}^{+}$diffusion in the bulk of conventional cathode materials, while disorder is generally considered as detrimental. Herein, we demonstrate that facile and reversible insertion and extraction of $\mathrm{Li}^{+}$ is possible with $\mathrm{LiVO}_{2}$, a new cation-disordered rock salt compound (space group: $\mathrm{Fm} \overline{3} \mathrm{~m}$ ), which is, to the best of our knowledge, described for the first time. This new polymorph of $\mathrm{LiVO}_{2}$ is synthesized by mechanical alloying. Rietveld refinements of the X-ray diffractions patterns and SAED (selected area electron diffraction) patterns attested the formation of the disordered $\mathrm{LiVO}_{2}$ rock salt phase. Galvanostatic cycling experiments were employed to characterize the electrochemical performance of the material, demonstrating that reversible cycling over 100 cycles with a discharge capacity around $100 \mathrm{mAh} \mathrm{g}^{-1}$ is possible.

\section{Introduction}

The most commonly applied cathode materials in lithium ion batteries (LIBS) are lithium transition metal (TM) layered oxides $\left(\mathrm{LiTMO}_{2}\right)$, amongst them $\mathrm{LiCoO}_{2}$, the first commercialized $\mathrm{Li}$ intercalation material. ${ }^{[1]} \mathrm{Up}$ to the present, various combinations of $\mathrm{LiTMO}_{2}$, with $\mathrm{Co}, \mathrm{Ni}$ and $\mathrm{Mn}$ as transition metals have been studied. ${ }^{[2]}$ These cathode materials have a well-defined layered crystal structure, which enables facile lithium deintercalation and intercalation in between the alternating layers of $\mathrm{Li}$ and $\mathrm{TM}$. Intermixing of the cations, due to Li diffusion within these layers, is regarded as ageing process, which lowers the battery performance..$^{[3,4]}$ Therefore, materials with $\mathrm{Li}$ and TM sharing the same sub-lattice in a cubic close packed array have been rather out of scope of the battery community in the past decades, until the paradigm change induced by various works of theoretical and experimental studies on disordered rock salt structures (DRS). ${ }^{[5-11]}$

Only few reports related to the electrochemical behavior of DRStype $\mathrm{LiTMO}_{2}$ compounds have been published so far. Above all, following elaborated investigations of Obrovac et al. with $\mathrm{TM}=\mathrm{Ti}$, $\mathrm{Mn}, \mathrm{Fe}$, $\mathrm{Co}$ and $\mathrm{Ni}$, the DRS oxides showed poor

[a] C. Baur, Dr. J. Chable, Dr. F. Klein, Dr. V. S. K. Chakravadhanula, Prof. M. Fichtner Helmholtz Institute Ulm Helmholtzstraße 11, 89081 Ulm (Germany) E-mail: m.fichtner@kit.edu

[b] Prof. M. Fichtner Institute of Nanotechnology, Karlsruhe Institute of Technology P.O. Box 3640, 76021 Karlsruhe (Germany)

[+] Presently at

Center for Materials Characterization and Testing, International Advanced Research Center for Powder Metallurgy and New Materials, Balapur P.O., Hyderabad, 500005 Telangana (India) electrochemical performance, compared to their layered analogous compounds (space group R $\overline{3} \mathrm{~m}$ ). ${ }^{[12]}$ In the case of $\mathrm{LiVO}_{2}$, almost only the layered polymorph was investigated as cathode material in the past. Electrochemical experiments revealed the migration of $\mathrm{V}$ into the layers of $\mathrm{Li}$, resulting in a distortion of the layered structure and a negligible discharge capacity (below $25 \mathrm{mAh} \mathrm{g}^{-1}$ for the first discharge). ${ }^{[13-15]}$ Nevertheless, off-stoichiometric layered $\mathrm{Li}_{1+x} \mathrm{~V}_{1-x} \mathrm{O}_{2}$ structures, like $\mathrm{Li}_{0.78} \mathrm{~V}_{0.75} \mathrm{O}_{2}$, could still be used as anode material in lithium ion batteries, as proposed by Zhang and coworkers. ${ }^{[16,17]}$ During studies of $\mathrm{V}$ migration in layered $\mathrm{LiVO}_{2}$, de Picciotto, Thackeray et al. investigated the lithiation of spinel $\mathrm{LiV}_{2} \mathrm{O}_{4}$ and the delithiation of layered $\mathrm{LiVO}_{2}$. The latter experiment led to substoichiometric rock salt phases (e.g. $\left.\mathrm{Li}_{0.22} \mathrm{VO}_{2}\right)^{[14,18]}$, whereas the former resulted in the formation of spinel $\mathrm{Li}_{2} \mathrm{~V}_{2} \mathrm{O}_{4}$, which is $\mathrm{LiVO}_{2}{ }^{[15]}$ One should note here that the spinel phase (space group $F d \overline{3} m$ ) is structurally closely related to the DRS (space group $F m \overline{3} \mathrm{~m}$ ). In fact, a mechanism of the spinel-to-DRS transition was proposed, as a possible continuation of the $\mathrm{LiV}_{2} \mathrm{O}_{4}$ spinel lithiation phenomenon. ${ }^{[19]}$. But, despite different synthesis approaches, this hypothetical DRS phase of $\mathrm{LiVO}_{2}$ was never obtained and the closest structure detected was still the spinel, sometimes accompanied by weak reflections of a rock salt superstructure [20], or mixed with the layered $\mathrm{LiVO}_{2}$ phase. ${ }^{[21]}$ Therefore, to the best of our knowledge, stoichiometric $\mathrm{LiVO}_{2}$ with a disordered rock salt structure has so far not been investigated as cathode material in LIBs. One reason could be the lack of a facile synthesis producing disordered rock salt phases.

Mechanochemical synthesis by high-energy ball milling is a simple and powerful technique, which can be used to obtain metastable phases. ${ }^{[22-24]}$ By applying this method we synthesized a new nanostructured polymorph of $\mathrm{LiVO}_{2}$ (space group $\mathrm{Fm} \overline{3} \mathrm{~m}$ ) with a disordered rock salt structure, directly from the precursor compounds $\mathrm{Li}_{2} \mathrm{O}$ and $\mathrm{V}_{2} \mathrm{O}_{3}$. The structure and morphology were characterized by Powder $\mathrm{X}$-ray diffraction (PXRD), High-resolution transmission electron microscopy (HRTEM) and Scanning electron microscopy (SEM).

Additionally, we investigated $\mathrm{LiVO}_{2}$ as cathode material for LIBs in a potential range of 1.9-3.0 V. The material exhibited a stable cycling behavior with an initial discharge capacity of $114 \mathrm{mAh} \mathrm{g}^{-1}$ at a current density of $50 \mathrm{~mA} \mathrm{~g}^{-1}(\mathrm{C} / 6$ rate) and an average discharge capacity of around $100 \mathrm{mAh} \mathrm{g}^{-1}$ over 100 cycles with an average discharge potential of $2.4 \mathrm{~V} \mathrm{vs}$. $\mathrm{Li}^{2} \mathrm{Li}^{+}$. 


\section{Results and Discussion}

Powder X-ray diffraction (PXRD) measurements were conducted to analyze the crystalline structure of $\mathrm{LiVO}_{2}$ synthesized by highenergy ball milling. The PXRD pattern of the as-prepared $\mathrm{LiVO}_{2}$ shows a cubic structure, clearly different from the well described trigonal phase of $\mathrm{LiVO}_{2}$ (space group $\mathrm{R} \overline{3} \mathrm{~m}$, Figure 1). ${ }^{[14,25]}$

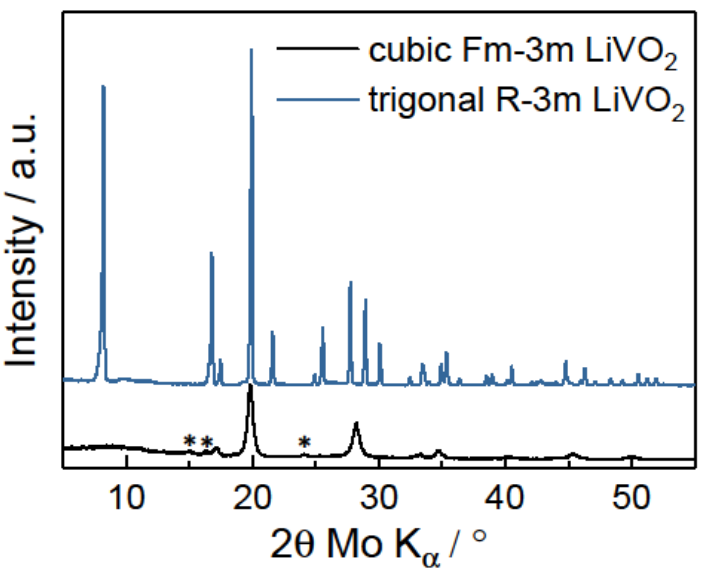

Figure 1. PXRD pattern of disordered rock salt $(\mathrm{Fm} 3 \overline{\mathrm{m}}) \mathrm{LiVO}_{2}$ (black, * for $\mathrm{V}_{2} \mathrm{O}_{3}$ unreacted precursor) and trigonal $\left(\mathrm{R}^{-} \mathrm{m}\right) \mathrm{LiVO}_{2}$ (blue).

The XRD pattern of the cubic $\mathrm{LiVO}_{2}$ is mainly characterized by broad reflections and an amorphous contribution in the low $2 \theta$ region $\left(5^{\circ}\right.$ to $\left.12^{\circ}\right)$, indicating a nanocrystalline nature of the compound. First phase identification was not unambiguous and suggested two possibilities, a spinel or a disordered rock salt phase. The spinel phase (space group $\mathrm{Fd} \overline{3} \mathrm{~m}$ ) corresponds to the phase obtained by lithiation of $\mathrm{LiV}_{2} \mathrm{O}_{4}$ or under high pressure conditions ${ }^{[19,21,26]}$, whereas the disordered rock salt structure (space group $F m \overline{3} \mathrm{~m}$ ) is equal to phases obtained under similar synthesis conditions (high-energy ball milling). ${ }^{[9,12]}$ Rietveld refinements were thus undertaken to discriminate both space groups. Results point towards the Fm $\overline{3} \mathrm{~m}$ space group by comparison of the $R_{\text {Bragg }}$ factors obtained $(5.3 \%$ vs. $6.6 \%$ for $\mathrm{Fd} \overline{3} \mathrm{~m})$, as well as the absence in our samples of the high (111) reflection, characteristic of the spinel phase (Figure S1). Following the Hamilton's test (Table S1), this $\mathrm{R}_{\text {Bragg }}$ difference is significant enough to confirm that the disordered rock salt phase was synthesized. More information on the refinement procedure is given in Table S2 and will be described in more details in a forthcoming study on the structural links between the different $\mathrm{LiVO}_{2}$ polymorphs. The optimal refinement performed with the $\mathrm{Fm} \overline{3} \mathrm{~m}$ space group is presented in Figure 2 and yielded a lattice constant $a=4.116(2) \AA$. Lithium and vanadium cations both share the same $4 \mathrm{a}$ Wyckoff sites with an occupancy ratio calculated as 1.06:1. Precise Li-excess quantification cannot be trusted, given that accurate determination of atomic occupancy rates based on XRD data of nanoscale ball-milled materials with a cubic phase is nearly impossible, due to the low number of reflections and their low intensities. Nevertheless, a Li-excess in the range of $1 \%$ to $11 \%$ was systematically calculated during refinements of the as-prepared samples and could be related to the incomplete incorporation of $\mathrm{V}_{2} \mathrm{O}_{3}$ precursor (even under optimized milling conditions), as observed on the PXRD pattern (Figure 2) and confirmed by the refinement $(\approx 2.4 \%$ of unreacted vanadium precursor). Furthermore, it should be noted that unreacted $\mathrm{Li}_{2} \mathrm{O}$ precursor could exist even if it was not detected as a crystalline phase by XRD as it could be present in the amorphous fraction of the samples. Therefore, it was not possible to determine the exact composition of this possibly slightly un-stoichiometric DRS $\mathrm{LiVO}_{2}$. Microstructural information was also obtained as described in more detail in the experimental part. The small average apparent crystallite size calculated is $11(1) \mathrm{nm}$, as can be expected from hard ball-milling conditions. ${ }^{[23,24,27]}$

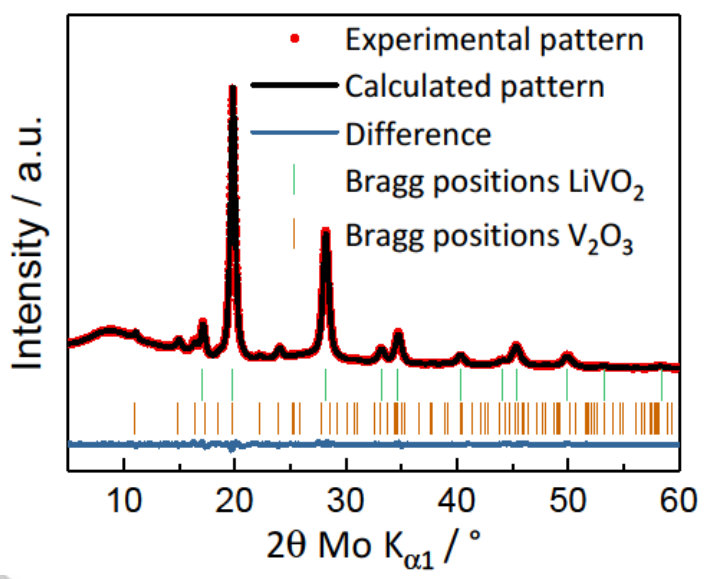

Figure 2. Rietveld refinement of the XRD pattern of disordered rock salt $(\mathbf{F m} \overline{3} \mathbf{m}) \mathrm{LiVO}_{2}$. Trigonal $\mathrm{V}_{2} \mathrm{O}_{3}(\mathrm{R} \overline{\mathbf{3}} \mathrm{c})$ was identified as unreacted precursor (PDF\#00-034-0187)

Transmission electron microscopy (TEM) studies were conducted to further investigate the morphology, structure and chemical composition of the synthesized $\mathrm{LiVO}_{2}$ compound. Figure $3 \mathrm{a}$ shows the HRTEM micrograph of $\mathrm{LiVO}_{2}$ and the corresponding fast Fourier transformation (FFT) from the marked area as an inset. The FFT shows the reflection at $2.36 \AA$ corresponding to the metrics from (1 111 ) plane. The d-values measured from the indexed selected area electron diffraction (SAED) pattern with an overlay of the integrated intensity distribution profile (Figure $3 b$ ) correspond to the metrics of the $\mathrm{Fm} \overline{3} \mathrm{~m}$ disordered rock salt crystal system of $\mathrm{LiVO}_{2}$ : $2.36 \AA$ ( $\left.\begin{array}{lll}1 & 1 & 1\end{array}\right), 2.04 \AA$ (0 02 2), $1.44 \AA$ (0 2 2 2) and $1.18 \AA$ (2 2 2), revealing the nanocrystalline character of the material. These $d$ values are in good agreement with the results of the Rietveld refinement and XRD studies. Scanning electron microscope (SEM) images (Figure 3c, d) reveal heterogeneous secondary particles consisting of agglomerated smaller primary particles with particle size variations in the sub-micrometer range. The shape seems to be roughly of a spherical nature.

Figure 4 shows the electron energy loss spectra (EELS) depicting the $\mathrm{V}-\mathrm{M}_{2,3}, \mathrm{Li}-\mathrm{K}, \mathrm{V}-\mathrm{L}_{3}, \mathrm{~V}-\mathrm{L}_{2}$ and $\mathrm{O}-\mathrm{K}$ regions. Their background was subtracted by power-law fitting in the pre-edge region of the spectrum. Apart from their absolute edge positions, 
their fine structure agrees well with other publications for $\mathrm{V}$. ${ }^{[28,29]}$ The O-K edge onset position of $\mathrm{LiVO}_{2}$ is difficult to observe since it overlaps with the continuum region of the $V-L_{2,3}$ edge. Apart from that, the O-K edge also shows a considerable shift of the onset position, which cannot be unambiguously revealed from conventional EELS without accurate energy scale calibration. However, it is important to point out that the both V$\mathrm{L}_{2,3}$ and $\mathrm{O}-\mathrm{K}$ edge onset indicate, in comparison with the literature, ${ }^{[28,29]}$ the oxidation state of $\mathrm{V}$ to be in $3+$ state.
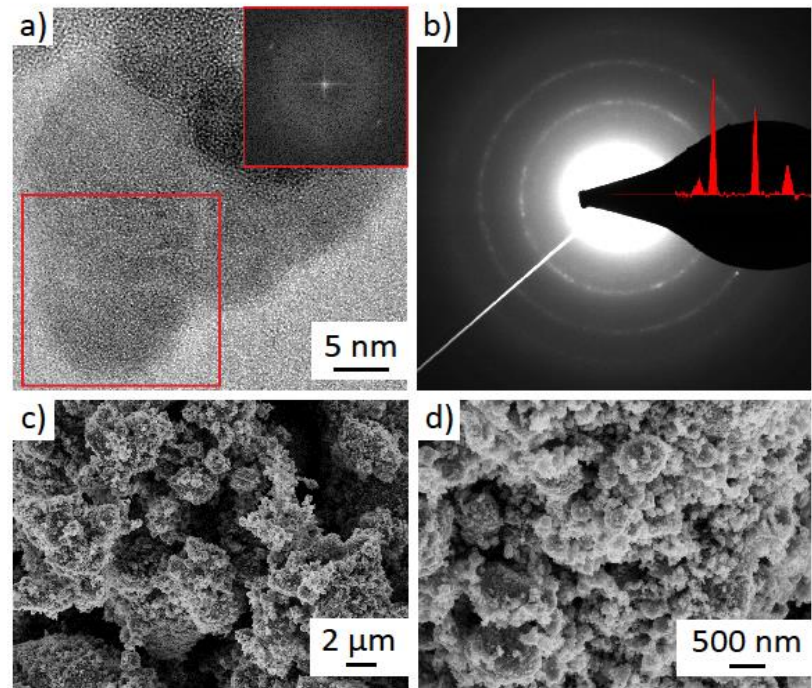

Figure 3. a) High-resolution TEM micrograph of $\mathrm{LiVO}_{2}$ with the corresponding fast Fourier transformation (FFT) image (inset); b): Selected area electron diffraction (SAED) pattern of $\mathrm{LiVO}_{2} ; \mathrm{c}$ ) and d) Scanning electron micrographs (SEM) of $\mathrm{LiVO}_{2}$.

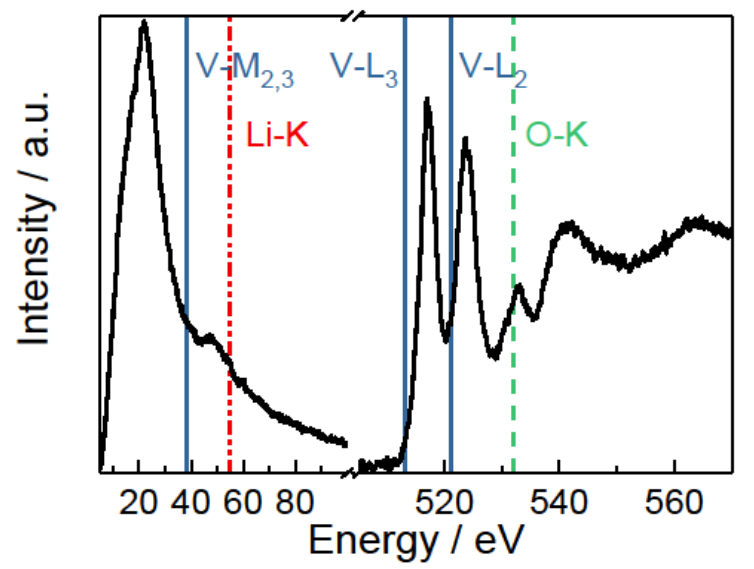

Figure 4. $\mathrm{V}-\mathrm{M}_{2,3}$, $\mathrm{Li}-\mathrm{K}, \mathrm{V}-\mathrm{L}_{2,3}$ and $\mathrm{O}-\mathrm{K}$ electron energy loss spectra of $\mathrm{LiVO}_{2}$, where the dashed lines indicate the marked peak positions revealing the oxidation state of $\mathrm{V}$ to be $3+$.

The electrochemical behavior of $\mathrm{DRS} \mathrm{LiVO}_{2}$ as cathode material for LIBs was investigated. Figure $5 \mathrm{a}$ presents the cycling performance of $\mathrm{LiVO}_{2}$ disordered rock salt in lithium half-cells in the voltage range of $1.9-3.0 \mathrm{~V}$ applying a current density of $50 \mathrm{~mA} \mathrm{~g}^{-1}(\mathrm{C} / 6$ rate $)$ at $25^{\circ} \mathrm{C}$. Assuming the redox activity of the $\mathrm{V}^{3+} / \mathrm{V}^{4+}$ couple and the complete extraction of $\mathrm{Li}^{+}$-ions resulting in $\mathrm{VO}_{2}, \mathrm{LiVO}_{2}$ has a theoretical capacity of $298 \mathrm{mAh} \mathrm{g}^{-1}$. However, the expected capacity could be lower because a full delithiation could cause irreversible structural changes. This is already known from $\mathrm{LiCoO}_{2}$, for example, where only $0.5 \mathrm{M} \mathrm{Li}$ can be reversibly extracted. The discharge capacity in the first cycle after an initial formatting charge step is $114 \mathrm{mAh} \mathrm{g}^{-1}$ and the $2^{\text {nd }}$ charge capacity is $116 \mathrm{mAh} \mathrm{g}^{-1}$ (i.e. $98.3 \%$ Coulombic Efficiency). After 100 cycles, the capacity slightly decreases to $94 \mathrm{mAh} \mathrm{g}^{-1}$, which is $82.6 \%$ of the initial discharge capacity. The corresponding voltage profiles (Figure $5 b$ ) reveal a sloping behavior, supposing a single-phase insertion process (see exsitu XRD refinements, Figure 9). The steepness of the voltage profile slope corresponds to the $\mathrm{Li}^{+}$insertion into a fully disordered structure as proposed by Ceder et al..[7] Nevertheless, the first charging step distinguishes from the further charges. While the first charge starts at an open circuit voltage (OCV) of $2.67 \mathrm{~V}$ vs. $\mathrm{Li} / \mathrm{Li}^{+}$the further charges start at $1.9 \mathrm{~V}$. This means that during the first charge less Li-ions can be extracted than during all other charges resulting in a lower first charge capacity To differentiate between the first charge and the further charges we used to describe the first charge as a formatting step. The voltage profiles and the cycling performance over 100 cycles demonstrate the proof-of-concept for disordered rock salt $\mathrm{LiVO}_{2}$ phases to be reversibly delithiated. 

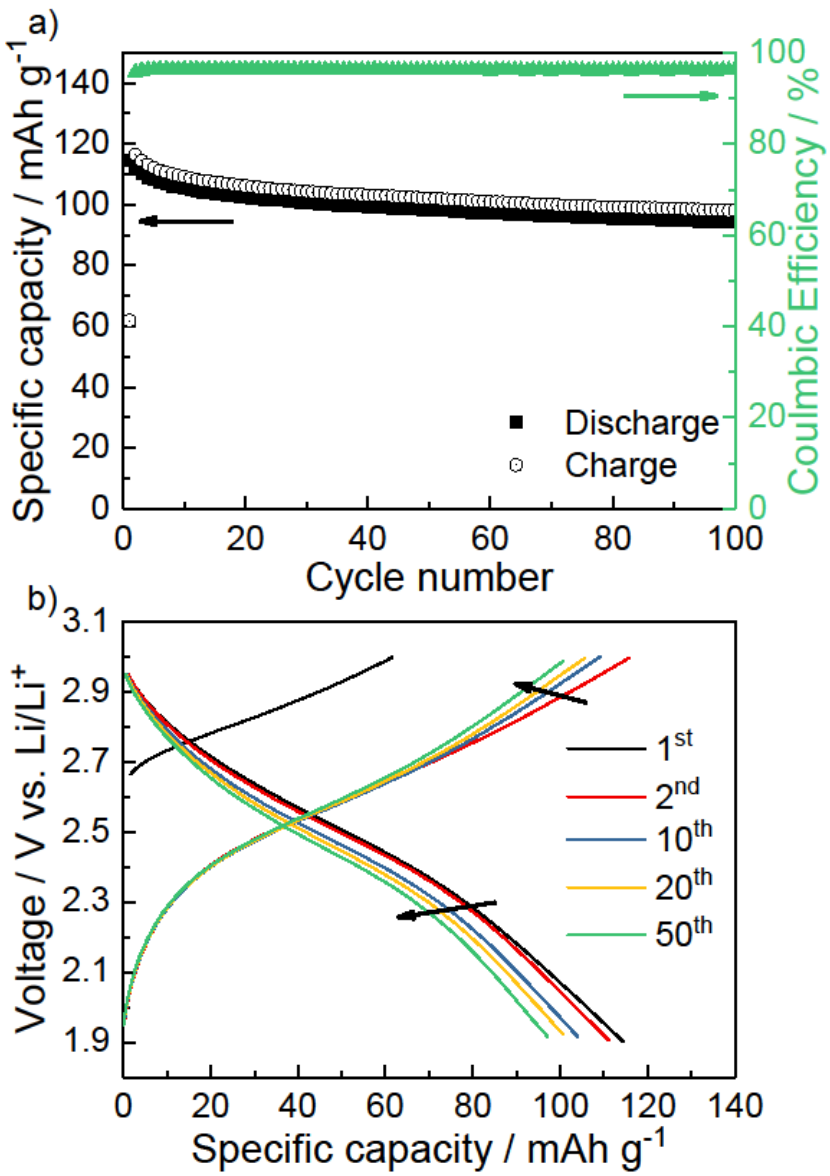

Figure 5. a) Cycling performance (filled squares: discharge capacity, open circles: charge capacity) and Coulombic Efficiency (green) as a function of cycle number and b) corresponding voltage profiles of $\mathrm{LiVO}_{2}$ half-cells cycled between 1.9-3.0 V vs. $\mathrm{Li}^{2} \mathrm{Li}^{+}$with a constant current of $50 \mathrm{~mA} \mathrm{~g}^{-1}$ at $25^{\circ} \mathrm{C}$.

To further enlarge the amount of extracted $\mathrm{Li}^{+}$out of the $\mathrm{LiVO}_{2}$ cathode material, the upper cut-off voltage was increased to $3.25 \mathrm{~V}$ and $3.5 \mathrm{~V}$. The increase of the cut-off potentials to $3.25 \mathrm{~V}$ and $3.5 \mathrm{~V}$ (Figure 6), led to higher discharge capacities of $153 \mathrm{mAh} \mathrm{g}^{-1}$ and $183 \mathrm{mAh} \mathrm{g}^{-1}$ during the initial discharge, respectively. The corresponding charge capacities increased, too. However, galvanostatic cycling over 100 cycles shows a distinct capacity fading for the broader voltage ranges (i.e. $75 \%$ of initial discharge capacity for $1.9 \mathrm{~V}$ to $3.25 \mathrm{~V}$ and $64 \%$ of initial discharge capacity for $1.9 \mathrm{~V}$ to $3.5 \mathrm{~V}$ ). The Coulombic Efficiencies after 100 cycles are $96 \%, 94 \%$ and $92 \%$ for the increasing upper cut-off potentials from $3.0 \mathrm{~V}$ to $3.25 \mathrm{~V}$ and $3.5 \mathrm{~V}$. This behavior indicates irreversible side reactions at the upper cut-off voltage. There are several mechanisms, which could explain this behavior and which may contribute to the observed capacity fading: (i) Dissolution of vanadium out of the cathode material could occur, which has already been observed for several vanadium oxide related materials. ${ }^{[30,31]}$ The small crystallite and particle size, the presence of an amorphous fraction in the pristine material ${ }^{[32]}$, as well as the increasing upper cut-off voltage could facilitate this dissolution. (ii) Decomposition of the structure to some extent at higher cutoff voltages could take place and (iii) reactions of the electrolyte with the electrode interface along with catalytic electrolyte degradation due to the nanocrystalline structure could be possible, too.

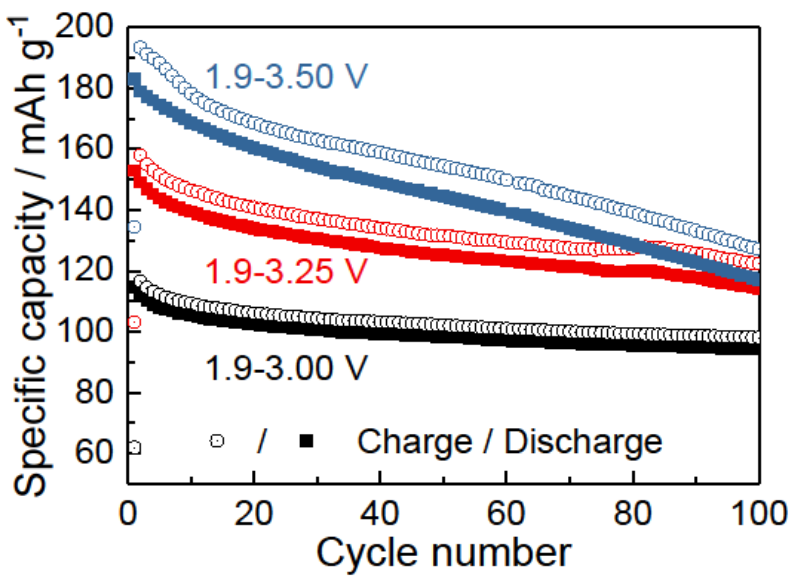

Figure 6. Cycling performance (open circles: charge capacity; filled squares: discharge capacity) of $\mathrm{LiVO}_{2}$ half-cells cycled between 1.9-3.00 V (black), 1.9$3.25 \mathrm{~V}$ (red) and $1.9-3.50 \mathrm{~V}$ (blue) vs. $\mathrm{Li}^{2} \mathrm{Li}^{+}$as a function of cycle number with a constant current density of $50 \mathrm{~mA} \mathrm{~g}^{-1}$.

To better understand the capacity fading with increasing upper cut-off voltage, differential capacity experiments were conducted. The analysis of the differential capacity $\mathrm{dQ} / \mathrm{dV}$ for several cycles within different voltage ranges is presented in Figure 7 . The broad redox peaks in the second cycle are located at $2.55 \mathrm{~V}$ during charge and at $2.50 \mathrm{~V}$ during discharge, indicating a small voltage deviation of $50 \mathrm{mV}$ between discharge and charge peak. In case of the narrow 1.9-3.00 V voltage range, only a minor increase of this deviation ( $108 \mathrm{mV}$ ) is observed after 100 cycles. When cycled within the larger cut-off potentials of 1.9-3.25 $\mathrm{V}$ and 1.9-3.5 $\mathrm{V}$ the increase of this voltage deviation is more pronounced, especially for the largest voltage range $(260 \mathrm{mV}$ vs. $357 \mathrm{mV}$ ). These voltage deviations between discharge and charge peak in the $\mathrm{dQ} / \mathrm{dV}$ plot could be explained as follows: The electrode kinetics can be affected by several factors such as surface energy, crystallinity, and diffusion of ions. Nanoparticles, e.g. DRS $\mathrm{LiVO}_{2}$, exhibit a large surface area (and large interfacial area) and therefore higher surface energies compared to bulk leading to deviations in theoretical cell potential of the system. ${ }^{[33]}$ Changes during discharge, charge and upon extended cycling could thus contribute to deviations. Li-ion diffusion, which could change upon cycling due to disorder [5,34] may increase the kinetic polarization. Besides these reversible changes in $\mathrm{LiVO}_{2}$, irreversible changes could also occur during cycling: e.g. vanadium dissolution and electrolyte degradation. These irreversible processes also result in deviations from the theoretical cell potential. This means that the observed shifts of the peak potentials in the differential capacity plot can arise by both, reversible and irreversible deviations.

To investigate the rate capability of $\mathrm{LiVO}_{2}$ cathode materials, the electrodes were cycled with various current densities in a voltage range of $1.9 \mathrm{~V}$ to $3.0 \mathrm{~V}$ (Figure 8). The discharge 
capacities are $123 \mathrm{mAh} \mathrm{g}^{-1}, \quad 110 \mathrm{mAh} \mathrm{g}^{-1}, \quad 98 \mathrm{mAh} \mathrm{g}^{-1}$, $81 \mathrm{mAh} \mathrm{g}^{-1}$ and $56 \mathrm{mAh} \mathrm{g}^{-1}$ for $\mathrm{C} / 30, \mathrm{C} / 15, \mathrm{C} / 6, \mathrm{C} / 3$ and $\mathrm{C} / 1.5$, respectively. Increasing current density leads to a reduction of discharge capacities because the ohmic polarization increases and as a consequence, the average discharge potential is lowered. When increasing the current density back to $\mathrm{C} / 6$, $92 \mathrm{mAh} \mathrm{g}^{-1}$ can be achieved revealing a good rate capability. Increasing current density also results in improving Coulombic Efficiencies. At higher C-rates the $\mathrm{LiVO}_{2}$ has a shorter interaction time at higher potentials with the electrolyte, which means that mostly the cell reaction (i.e. the reversible extraction of $\mathrm{Li}^{+}$) takes place and the unwanted side reactions (i.e. irreversible vanadium dissolution and electrolyte degradation) plays only a minor role. This higher degree of reversibility then leads to improved Coulombic Efficiencies. These results are well in line with the higher efficiencies found for the smaller voltage range window, where side reactions are partly avoided, and the lower efficiencies at higher cut-off potentials, where the degree of irreversibility increases (see Figure 6).

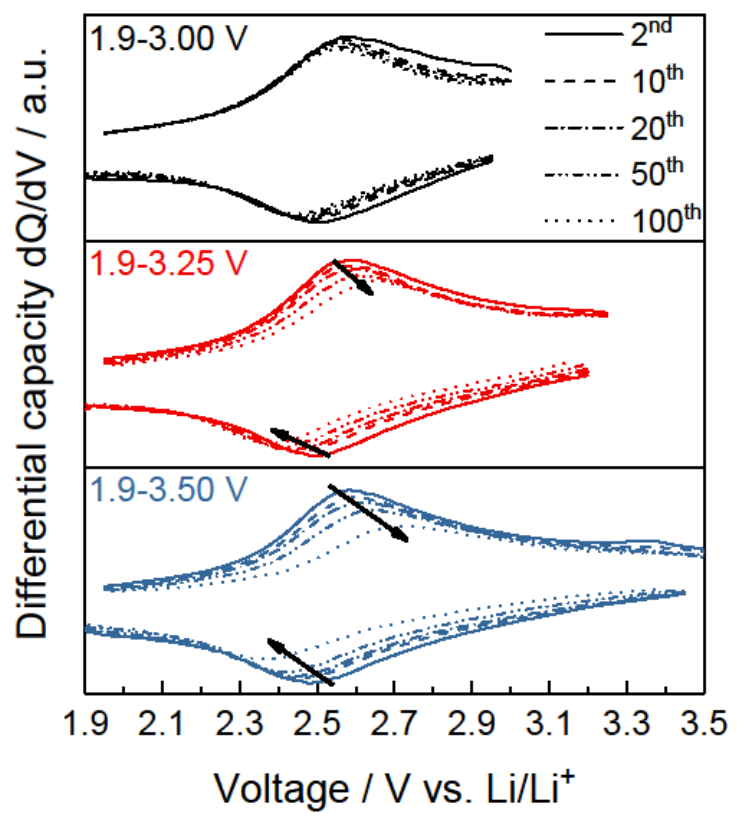

Figure 7. Differential capacity $d Q / d V$ plots of $\mathrm{LiVO}_{2}$ half-cells cycled between 1.9-3.00 V, 1.9-3.25 $\mathrm{V}$ and $1.9-3.5 \mathrm{~V}$ vs. $\mathrm{Li}^{\prime} / \mathrm{Li}^{+}$with a constant current density of $50 \mathrm{~mA} \mathrm{~g}^{-1}$ at $25^{\circ} \mathrm{C}$.

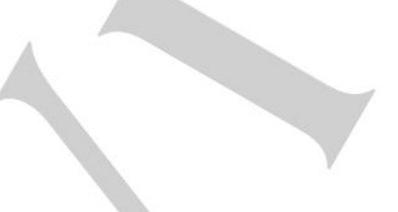

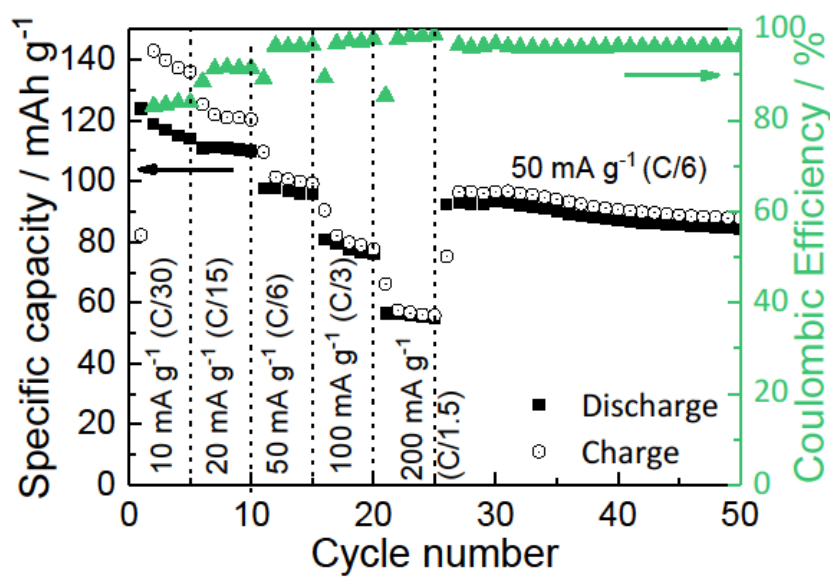

Figure 8. Rate capability of $\mathrm{LiVO}_{2}$ half-cells (open circles: charge capacity, filled squares: discharge capacity, green: Coulombic Efficiency) with various current densities in a voltage range of $1.9-3.0 \mathrm{~V} \mathrm{vs}$. $\mathrm{Li} / \mathrm{Li}^{+}$at $25^{\circ} \mathrm{C}$.

For a better understanding of the electrochemical behavior of $\mathrm{LiVO}_{2}$ cathode materials, ex-situ X-ray diffractions studies have been conducted at different cut-off voltages and after prolonged cycling to examine possible changes in the crystal structure of $\mathrm{LiVO}_{2}$ during cycling (Figure 9a and Figure S2). As can be seen after the first charge and discharge, $\mathrm{LiVO}_{2}$ exhibits slight structural changes when cycled between 3.0-1.9 V (compared with the pristine material). The lattice parameter $a$, as well as the lattice volume $V$ (see Figure 9b), almost linearly changes upon cycling, suggesting a reversible single-phase insertion process, as already observed in related disordered rock salt materials,,$[9,35]$ and which is also in line with the observed voltage profiles (Figure $5 \mathrm{~b}$ ). $a$ and $V$ decrease during charge with $\mathrm{Li}^{+}$extraction, and increase during discharge, with $\mathrm{Li}^{+}$insertion. The overall lattice volume varies only by $2.1 \%$ in this voltage window, again similarly to recently reported DRS materials. ${ }^{[9,35]}$ When fully discharged, the lattice constant and lattice volume are slightly bigger than the initial values for the pristine material (1.0\%). This might be explained by an additional $\mathrm{Li}^{+}$uptake upon discharge in the defective lattice structure induced by the high-energy ball milling synthesis. ${ }^{[9,35]}$ However, no additional reflections for potential rock salt to spinel (with $\mathrm{Li}^{+}$insertion in tetrahedral $8 \mathrm{a}$ sites) or rock salt to layered phase transitions are observed in the pattern. This means the DRS structure is maintained during cycling and no irreversible phase transition seems to take place, at least until the $10^{\text {th }}$ cycle (Figure S2). Nevertheless, due to the nanocrystalline nature of the material and the weak scattering power of $\mathrm{Li}$, this cannot be completely excluded and could be ruled out only by further structural ex-situ studies, e.g. using neutron diffraction and/or solid-state NMR measurements. 
a)
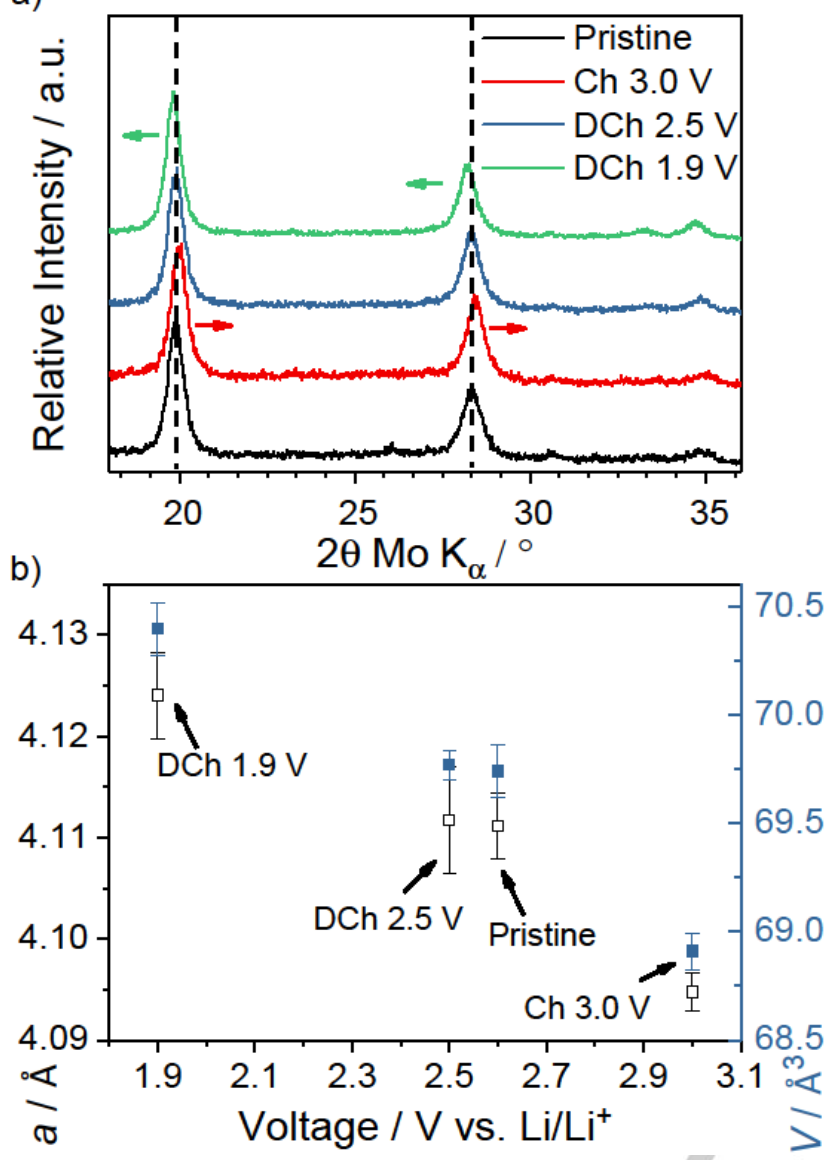

Figure 9. a) Ex-situ XRD patterns of cycled $\mathrm{LiVO}_{2}$ electrodes at different states of charge and discharge (black: pristine electrode, red: fully charged to $3.0 \mathrm{~V}$ vs. $\mathrm{Li} / \mathrm{Li}^{+}$, blue: discharged to $2.5 \mathrm{~V}$ and green: fully discharged to $1.9 \mathrm{~V}$ ) and $b)$ the corresponding changes in lattice constant $a$ and cell volume $V$ during cycling.

In summary, disordered rock salt $\mathrm{LiVO}_{2}$ shows an unexpected reversible electrochemical behavior upon lithium extraction and insertion, when compared to layered $\mathrm{LiVO}_{2}{ }^{[13,14]}$ and considering the rather negative effect of disorder on $\mathrm{Li}^{+}$diffusion, as reported for the other ball-milled DRS-type $\mathrm{LiTMO}_{2}$ compounds. ${ }^{[12]}$ Irreversible side reactions, presumably the dissolution of vanadium and decomposition of the electrolyte at higher potentials, reduce the cycling efficiency of this DRS $\mathrm{LiVO}_{2}$. The development of a particle coating might protect $\mathrm{LiVO}_{2}$ to mitigate unwanted reactions and to improve the cycling stability, which could enable access to larger cut-off voltage ranges, thus increasing the overall cycling performance. The results indicate a single-phase $\mathrm{Li}^{+}$insertion and extraction, but the mechanism of the $\mathrm{Li}^{+}$diffusion yet remains unclear and is object of further investigations. In principle, nanoscale dimensions, amorphous contributions and high defect concentrations may enhance lithium diffusion. ${ }^{[36,37]}$ In addition, the slight off-stoichiometry in the Li/V-ratio could be a reason for the enhanced macroscopic bulk diffusion, as theoretically proposed by Ceder et al. for Liexcess cation disordered rock salt materials. ${ }^{[5,34]}$ These first hypotheses have to be examined and further investigation of the crystal structure of the compound, including an optimization of the synthesis and possible thermal post-treatments to obtain a more crystallized material, is underway to shed light on the $\mathrm{Li}^{+}$ diffusion mechanism in the material.

\section{Conclusions}

In conclusion, we report the synthesis of a new polymorph of $\mathrm{LiVO}_{2}$ exhibiting a disordered rock salt structure $(\mathrm{Fm} \overline{3} \mathrm{~m})$ by a simple mechanochemical ball milling approach. Furthermore, we demonstrate the electrochemical behavior of this disordered rock salt $\mathrm{LiVO}_{2}$ as an interesting new material regarding reversible delithiation. Despite the disordered crystal structure, the material shows a reversible and stable cycling behavior over 100 cycles. Nevertheless, the full theoretical capacity of the material cannot be achieved, at least without phase transition. Attempts to increase the obtained capacity by increasing the upper cut-off voltage lead to undesirable irreversible side reactions. This work is one further step towards better understanding of the promising new class of cathode materials with a disordered rock salt structure.

\section{Experimental Section}

$\mathrm{LiVO}_{2}$ was prepared by using a dry ball milling procedure $(600 \mathrm{rpm}$ for $20 \mathrm{~h}$, Fritsch Pulverisette 6 classic line, $80 \mathrm{~mL} \mathrm{Si}_{3} \mathrm{~N}_{4}$ jar and 25 balls of $10 \mathrm{~mm}$ diameter) using $\mathrm{Li}_{2} \mathrm{O}$ (99.5\%, Alfa Aesar) and $\mathrm{V}_{2} \mathrm{O}_{3}(99.7 \%$, Alfa Aesar) as precursors. The precursor compounds were filled into the $\mathrm{Si}_{3} \mathrm{~N}_{4}$ jar under inert conditions in an argon-filled glovebox with water and oxygen levels below $0.1 \mathrm{ppm}$. After the synthesis, the $\mathrm{LiVO}_{2}$ powder was handled in the glovebox and was used without further purification.

PXRD patterns were recorded in transmission geometry using a STOE STADI-p diffractometer with Mo $K_{\alpha 1}$ radiation $(0.70932 \AA$ ), equipped with a DECTRIS MYTHEN $1 \mathrm{~K}$ strip detector. Rietveld refinements were conducted on long-time collected XRD patterns (16 h), using the FullProf Software. ${ }^{[38]}$ Instrumental broadening was taken into account using $\mathrm{LaB}_{6}$ reference diffraction data. The sample contribution to X-ray line broadening was calculated by using the Thompson-Cox-Hastings pseudo-Voigt function that includes both size and strain-broadening terms for Lorentzian and Gaussian components. ${ }^{[39]}$ The apparent crystallite size $<L>$ and the upper limit of microstrain are then internally calculated by FullProf using Langford's method. ${ }^{[40]}$

Transmission electron microscopy (TEM) characterization was carried out using an aberration-corrected FEI Titan 80-300 microscope operated at $80 \mathrm{kV}$ and equipped with a Gatan imaging filter (Tridiem 863). For the (S)-TEM measurements, samples were prepared by dispersing a small amount of powder directly onto holey carbon Au grids (Quantifoil $\mathrm{GmbH}$ ). The SAED integrated intensity distribution profiles have been created by using PASAD script for Gatan Digital Micrograph.

Scanning electron microscopy was conducted with a ZEISS LEO 1550VP Field Emission SEM with in-lens detection at $5 \mathrm{keV}$, using conductive carbon tape as the substrate. The samples were shortly exposed to air during the transfer between glovebox to the SEM. 
Electrodes were prepared by mixing $\mathrm{LiVO}_{2}$ with carbon black (acetylene black, from Alfa Aesar) and a PVDF (polyvinylidenedifluoride) binder (from Sovley 6050) in N-Methyl-2-pyrrolidon (NMP, from Alfa Aesar) as solvent to obtain a slurry with a weight ratio of $75 / 20 / 5$. The slurry was coated on an aluminium foil acting as current collector and subsequently dried under vacuum at $120^{\circ} \mathrm{C}$ for $12 \mathrm{~h}$. Afterwards electrodes of $12 \mathrm{~mm}$ diameter were punched out. The active material mass loading was 1.8$2.2 \mathrm{mg} \mathrm{cm}^{-2}$.

For the electrochemical measurements 2-electrode Swagelok-type cells were assembled using a lithium metal counter electrode, and a $\mathrm{LiVO}_{2}$ working electrode, LP30-electrolyte (1 $\mathrm{MLiPF}_{6}$ in ethylene carbonate (EC)/ dimethyl carbonate (DMC) mixture (1:1 by volume, from Sigma Aldrich)) and Whatman glass fiber separators. These Li half-cells were assembled in a glovebox under Ar atmosphere. Galvanostatic chargedischarge tests were conducted with an ARBIN BT2000 battery testing system, with current densities of $10-200 \mathrm{~mA} \mathrm{~g}^{-1}$ in different voltage ranges $\left(1.9 \mathrm{~V}\right.$ to $3.0 \mathrm{~V}, 3.25 \mathrm{~V}$ and $3.5 \mathrm{~V}$ vs. $\left.\mathrm{Li}^{-1} \mathrm{Li}^{+}\right)$. All cells were left under open circuit voltage $(\mathrm{OCV})$ for $12 \mathrm{~h}$ before running electrochemical experiments and all measurements were carried out at $25^{\circ} \mathrm{C}$.

\section{Acknowledgements}

This project has received funding from the European Union's Horizon 2020 research and innovation programme under grant agreement No 711792 (FET-OPEN project LiRichFCC). The authors acknowledge the support of the Karlsruhe Nano Micro Facility for Electron Microscopy and Spectroscopy. Dr. Venkata Sai Kiran Chakravadhanula acknowledges the continued support of Christian Kübel.

Keywords: disordered rock salt $\cdot$ lithium ion batteries $\cdot$ cathode material $\cdot \mathrm{LiVO}_{2} \cdot$ high-energy ball milling

[1] K. Mizushima, P. C. Jones, P. J. Wiseman, J. B. Goodenough, Mater. Res. Bull. 1980, 15, 783-789.

[2] M. S. Whittingham, Chem. Rev. 2004, 104, 4271-4301.

[3] J. B. Goodenough, Y. Kim, Chem. Mater. 2010, 22, 587-603.

[4] J. Vetter, P. Novák, M. R. Wagner, C. Veit, K. C. Möller, J. O. Besenhard, M. Winter, M. Wohlfahrt-Mehrens, C. Vogler, A. Hammouche, J. Power Sources 2005, 147, 269-281.

[5] J. Lee, A. Urban, X. Li, D. Su, G. Hautier, G. Ceder, Science. 2014, 343, 519-522.

[6] A. Urban, J. Lee, G. Ceder, Adv. Energy Mater. 2014, 4, 1400478.

[7] A. Abdellahi, A. Urban, S. Dacek, G. Ceder, Chem. Mater. 2016, 28, 5373-5383.

[8] R. Wang, X. Li, L. Liu, J. Lee, D. H. Seo, S. H. Bo, A. Urban, G. Ceder, Electrochem. commun. 2015, 60, 70-73.

[9] R. Chen, S. Ren, M. Knapp, D. Wang, R. Witter, M. Fichtner, H. Hahn, Adv. Energy Mater. 2015, 5, 1401814.

[10] S. Ren, R. Chen, E. Maawad, O. Dolotko, A. A. Guda, V. Shapovalov, D. Wang, H. Hahn, M. Fichtner, Adv. Sci. 2015, 2, 1500128.

[11] R. Chen, S. Ren, M. Yavuz, A. a. Guda, V. Shapovalov, R. Witter, M. Fichtner, H. Hahn, Phys. Chem. Chem. Phys. 2015, 17, 1728817295.
[12] M. Obrovac, O. Mao, J. R. Dahn, Solid State lonics 1998, 112, 9-19.

[13] L. Zhang, K. Takada, N. Ohta, M. Osada, T. Sasaki, J. Power Sources 2007, 174, 1007-1011.

[14] L. A. de Picciotto, M. M. Thackeray, W. I. F. David, P. G. Bruce, J. B Goodenough, Mater. Res. Bull. 1984, 19, 1497-1506.

[15] L. A. De Picciotto, M. M. Thackeray, Solid State lonics 1986, 18-19, 773-777.

[16] A. R. Armstrong, C. Lyness, P. M. Panchmatia, M. S. Islam, P. G. Bruce, Nat. Mater. 2011, 10, 223-229.

[17] W. Zhang, J. Luo, X. Li, J. Liang, Y. Zhu, Y. Qian, J. Mater. Chem. A 2017, 5, 5148-5155.

[18] L. A. De Picciotto, M. M. Thackeray, G. Pistoia, Solid State Ionics 1988, 28, 1364-1370.

[19] L. A. De Picciotto, M. M. Thackeray, Mater. Res. Bull. 1985, 20, 1409-1420.

[20] C. Chieh, B. L. Chamberland, A. F. Wells, Acta Crystallogr. Sect. B 1981, 37, 1813-1816.

[21] T. A. Hewston, B. L. Chamberland, J. Solid State Chem. 1985, 59, 168-173.

[22] P. Baláž, M. Achimovičová, M. Baláž, P. Billik, Z. CherkezovaZheleva, J. M. Criado, F. Delogu, E. Dutková, E. Gaffet, F. J. Gotor, et al., Chem. Soc. Rev. 2013, 42, 7571-7637.

[23] C. Suryanarayana, Prog. Mater. Sci. 2004, 46, 1-184.

[24] V. Šepelák, A. Düvel, M. Wilkening, K.-D. Becker, P. Heitjans, Chem. Soc. Rev. 2013, 42, 7509.

[25] L. P. Cardoso, D. E. Cox, T. A. Hewston, B. L. Chamberland, J. Solid State Chem. 1988, 72, 234-243.

[26] L. A. De Picciotto, M. M. Thackeray, Mater. Res. Bull. 1985, 20, 187-195.

[27] J. Chable, A. G. Martin, A. Bourdin, M. Body, C. Legein, A Jouanneaux, M. P. Crosnier-Lopez, C. Galven, B. Dieudonné, M. Leblanc, et al., J. Alloys Compd. 2017, 692, 980-988.

H. Tan, J. Verbeeck, A. Abakumov, G. Van Tendeloo, Ultramicroscopy 2012, 116, 24-33.

[29] L. Fitting Kourkoutis, Y. Hotta, T. Susaki, H. Y. Hwang, D. A. Muller, Phys. Rev. Lett. 2006, 97, 256803.

[30] G. Sudant, E. Baudrin, B. Dunn, J.-M. Tarascon, J. Electrochem. Soc. 2004, 151, A666-A671.

[31] S. Jouanneau, A. Le Gal La Salle, A. Verbaere, D. Guyomard, J. Electrochem. Soc. 2005, 152, A1660-A1667.

[32] T. C. Arnoldussen, J. Electrochem. Soc. 1981, 128, 117-123.

[33] M. N. Obrovac, J. R. Dahn, Phys. Rev. B - Condens. Matter Mater. Phys. 2000, 61, 6713-6719.

[34] A. Urban, I. Matts, A. Abdellahi, G. Ceder, Adv. Energy Mater. 2016, $6,1600488$.

[35] X. Wang, Y. Huang, D. Ji, F. Omenya, K. Karki, S. Sallis, L. F. J. Piper, K. M. Wiaderek, K. W. Chapman, N. A. Chernova, et al., J. Electrochem. Soc. 2017, 164, A1552-A1558.

[36] M. Wilkening, V. Epp, A. Feldhoff, P. Heitjans, Society 2008, 3, 9291-9300.

[37] A. S. Aricò, P. Bruce, B. Scrosati, J.-M. Tarascon, W. van Schalkwijk, Nat. Mater. 2005, 4, 366-377.

[38] J. Rodríguez-Carvajal, Phys. B Condens. Matter 1993, 192, 55-69.

[39] P. Thompson, D. E. Cox, J. B. Hastings, J. Appl. Crystallogr. 1987, 
1

2

3

4

5

6

7

8

9

10

11

12

13

14

15

16

17

18

19

20

21

22

23

24

25

26

27

28

29

30

31

32

33

34

35

36

37

38

39

40

41

42

43

44

45

46

47

48

49

50

51

52

53

54

55

56

57

58

59

60

61

62

63

64

65

20, 79-83.

[40] J. I. Langford, J. Appl. Crystallogr. 1978, 11, 10-14. 